\title{
Enhancing CD-ROM Searches with Online Updates: An Examination of End-User Needs, Strategies, and Problems
}

\section{Susan K. Charles and Katharine E. Clark}

\begin{abstract}
Many academic researchers are interested in obtaining the most current information available when conducting computerized literature searches. A research project was conducted to evaluate the feasibility of providing an online updating service to end-users searching CD-ROM databases. Searchers using Silver Platter's Agricola database were asked to participate in the study. End-user searching strategies were observed and problems were noted. Factors such as cost-effectiveness and convenience were also studied. Data and observations indicate that endusers are interested in the availability of a low-cost, hybridized CD-ROM/online updating system. Conclusions are drawn concerning the future direction of online updating systems for end-users.
\end{abstract}

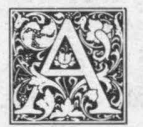

$t$ a growing number of research institutions, CD-ROM databases are becoming increasingly important, high-profile tools for conducting literature searches and represent the trend to streamline enduser search technologies. The high-usage levels of these products at Texas A\&M University's Evans Library is evidence of their popularity with a substantial segment of library patrons.

CD-ROM products offer patrons the opportunity to obtain information through inexpensive, user-friendly formats, but CD-ROM databases are not as current as their online counterparts. In CD-ROM database updating, manufacturing and marketing procedures such as file mastering, shipping, and processing cause delays that may be significant. ${ }^{1}$ Enhancement of these databases with online services can provide searchers with access to more current data. Online services and CD-ROM products can be coordinated to create a search environment in which patrons are provided with the most appropriate service. ${ }^{2}$ Creating a system where end-users can complement CD-ROM database searches with current citations from online updates may be a practical way of providing patrons with a more complete service option. Current library literature reveals no evidence of studies that examine the use of an online end-user system to enhance a database offered as a CD-ROM product, despite the existence of systems produced by DIALOG, Wilson, and Lotus. These systems allow patrons to switch conveniently from a CDROM database to the online counterpart.

Produced by Silver Platter, Agricola on CD-ROM is one of the most heavily used databases in the Reference Division of the Evans Library. This CD-ROM database is

Susan K. Charles is an Information Analyst for Hewlett-Packard Company Library MS 71, 3404 East Harmony Road, Ft. Collins, Colorado 80525-9599; and Katharine E. Clark is the Assistant Head of the Reference Division at the Sterling C. Evans Library of Texas AEM University, College Station, Texas 77843-5000. 
updated quarterly and patrons who utilize this service are not accessing the latest six to nine months of agricultural literature unless they supplement their CD-ROM searches with alternative options. Patrons can access Agricola online file updates by paying a slight fee ( $\$ 2.50$ or more) to use the After Dark end-user service, available in the evenings and on Saturdays. Patrons can also access Agricola online by scheduling a mediated online search. All patrons, except those graduate students who are entitled to receive one free mediated search each academic year, must pay a fee to cover connect, telecommunications, and citation charges for mediated searches. Because of its popularity, Agricola was an ideal target for a study that examined the use of an online updating system to complement end-user CD-ROM database searches.

\section{AVAILABILITY OF END-USER SERVICES AT THE EVANS LIBRARY}

At Texas A\&M University, the availability of a variety of low-cost or free end-user services could affect the level of end-user expertise and, consequently, the success of any particular strategy to coordinate the use of complementary online and CDROM databases. End-users have access to twenty-eight different laserdisk databases that utilize a variety of search techniques and command structures. Sixteen of these databases are located in the Wiley Laserdisk Service Area of the Reference Division and the remainder are available in other public service areas such as the Documents Division and Microtext Department. During a one-week period in April 1988, surveys collected in the Wiley Area indicated that 727 end-users had spent an average of 31 minutes using laserdisk databases. Agricola on CD-ROM ranked fourth highest in number of users. Approximately $70 \%$ of the laserdisk users were undergraduates. ${ }^{3}$

Another popular end-user service is the After Dark Service that enables students, faculty, and staff members to access approximately 150 databases through the BRS/After Dark, Knowledge Index, and STN systems. A generous gift from the Association of Former Students helps support connect costs for After Dark enduser searching by students, resulting in free access to all online databases available through Knowledge Index and substantially reduced charges for BRS/After Dark. Subsidized end-user searching is also available through IHS's Tech Data Service. During the 1987-88 academic year, 2,384 online end-user searches were performed for a total of 1532.77 online hours. The average cost to the patron for all After Dark end-user searches was \$.79. This figure includes free Knowledge Index searches, but the average cost to the patron for end-user searches that resulted in citation and/or connect charges was still low at $\$ 4.68$. Fifty-nine percent of endusers were graduate students, $35.5 \%$ were undergraduates, and $5.5 \%$ were University faculty or staff. ${ }^{4}$ These statistics are evidence that a substantial pool of Evans Library patrons do access a wide range of cost-effective end-user services.

\section{OBJECTIVES}

The Agricola online updating study was conducted to meet several main objectives. First, the study was used to determine if patrons searching Agricola on CDROM would be willing to use an online updating system to obtain more current citations. Second, the study measured the level of satisfaction that these patrons experienced after searching both Agricola on $\mathrm{CD}-\mathrm{ROM}$ and the online updating system. Finally, an estimation of the cost of such a service to the Library needed to be determined if this type of system were to be made available to all end-users currently searching Agricola on CD-ROM. Several types of "costs" were subsequently evaluated. These included: (1) tangible, quantitative costs such as online search changes, and (2) staff time requirements for coordinating this type of service and providing search assistance.

\section{METHODOLOGY}

A random sampling of CD-ROM Agricola users was conducted to select participants for the online updating study. The study was conducted over a 13-week period in 1988. Each week was divided into 501 -hour slots that were available for ran- 
dom selection. A random number table was used to select those slots during which users of Agricola on CD-ROM would be offered an opportunity to update their search by using Agricola online at no charge. The first CD-ROM Agricola user to arrive during each randomized slot was approached about participating in the study. Patrons who chose to participate concluded their search on the CD-ROM database and then contacted the investigator when they were ready to do their online search. Patrons who declined to participate completed a brief form to explain why they were not interested in updating their searches online.

After the search strategy was completed, the participant went online, conducted the search, and selected online prints.

Online Agricola searches were conducted using the DIALOG system and DIALOGLINK communications software. The type ahead feature of DIALOGLINK enables online users to type search statements offline. This feature was utilized for the updating study to allow participants to type and revise their searches at their own pace. Each participant was asked to read an instruction sheet that provided simplified, step-by-step instructions on conducting the search and using DIALOG search commands. A brief sample search was also provided. After reading the instructions, each participant began typing the search strategy previously employed for the CD-ROM search onto the appropriate DIALOGLINK screen. After the search strategy was completed, the participant went online, conducted the search, and selected online prints. All searches were limited to the most recent updates that included the last two months of coverage provided by the most current CDROM disk. Participants had a chance to examine the citations retrieved by their search during the printing process. Each session was monitored by one of the investigators.
A questionnaire was used to measure and evaluate the responses of the participants using the online system to update the CD-ROM searches. Participants provided information on their status (undergraduate, graduate, faculty, or other) and their familiarity with computers, databases, and end-user services. Participants were also asked to evaluate the Agricola online updating system in terms of ease of use, time needed to complete the search, problems encountered, and the need for assistance. The number of citations obtained from both the online and CD-ROM searches were recorded, and participants evaluated the relevancy and usefulness of the citations retrieved by the online system. Participants gave the online updating system an overall satisfaction rating and provided data on how frequently they would use the system if it were available on a permanent basis and what fees they would consider paying for the service. Many participants also provided additional comments on the online updating system.

\section{STUDY RESULTS}

A total of 87 1-hour randomized slots were monitored for end-users willing to participate in the study. Out of the 45 people who used Agricola on CD-ROM during these time periods, $30(67 \%)$ elected to update their searches using Agricola online. Of the 15 respondents who declined to utilize the online updating system, 8 stated that they did not have enough time to participate, 6 thought that they had already obtained enough information from Agricola on CD-ROM, and one respondent could not find appropriate information by using Agricola and selected another laserdisk database.

Twenty-six (58\%) of the 45 CD-ROM users who participated were graduate students, $16(35 \%)$ were undergraduates, and $3(7 \%)$ were university staff or community users. None of the participants was a faculty member. Eighteen $(60 \%)$ of the 30 users who conducted the online Agricola search were graduate students, 11 (37\%) were undergraduates, and $1(3 \%)$ was a university staff or community user. Twenty-seven $(90 \%)$ of the online updat- 
ing participants indicated that they had used a laserdisk or online database during the previous year.

\section{Search Results and Participant Satisfaction}

The mean number of citations retrieved by the Agricola online updating system was 38 , with a median of 1.5 . The maximum number of citations retrieved was 395 and $12(40 \%)$ of the searches retrieved no citations. Although $19(63 \%)$ of the online searches retrieved only 2 or fewer citations, $20(67 \%)$ of the participants thought that they had obtained enough citations to enhance their research efforts. When participants were asked, "How would you rate the overall results of online updating of Agricola/CD-ROM?," 25 (83\%) gave a rating of "satisfactory" or "very satisfactory." When asked, "If online updating for Agricola/CD-ROM was available on a regular basis, how often would you use it?", 24 (80\%) participants answered "often" or "always" (see figure 1). Twentysix participants $(87 \%)$ indicated that they would prefer "conducting searches using both Agricola/CD-ROM and the online updating system (with assistance)."

\section{Search Costs and Fees}

Actual search costs were recorded and cost per search ranged from $\$ .42$ to $\$ 98.97$. The mean cost of the online searches was $\$ 9.50$, with a median cost of $\$ 1.82$. Twenty-six of the searches $(87 \%)$ cost less than $\$ 10$ and 17 (57\%) cost less than $\$ 2$ (see figure 2).

Participants were queried about using the Agricola online updating system for a fee, and when asked, "If online updating for Agricola/CD-ROM was available for a modest fee (\$2 to \$5), how often would you use it?"', 22 (73\%) participants answered "never," "seldom," or "sometimes" (see figure 3). When the same question was rephrased, "If a fee were charged for online updating how much would you be willing to pay?," $100 \%$ of the participants indicated that they would pay $\$ 5$ or less. The responses to both questions indicate that the majority of patrons are only willing to pay under $\$ 5$ for online updating.

\section{OBSERVATIONS AND DISCUSSION}

The information gained from the researchers' observations on their subjects' searching behavior was as enlightening as the quantitative data supplied by the questionnaire. Because the researchers monitored the patrons while they did their DIALOG update searches, they were able to get a firsthand look at their search strategies. The observations made concerning these searches were revealing and led to the unexpected conclusion that the majority of the participants did not understand the basic concepts of searching, such as selection of search terms, use of Boolean operators, truncation, and limiting.

The participants did not understand the basic concepts of searching, such as selection of search terms, use of Boolean operators, truncation, and limiting.

The Evans Library at Texas A\&M University first offered end-users access to BRS/After Dark in 1984. Since that time, Knowledge Index and STN have been added. Users are required to read a manual before their appointment and to show the attendant their search terms. After discussing their terms and possible search strategy, the patrons are logged on to the appropriate online system. The attendant is available to answer questions at any time during the session. Both printed and personal assistance are available before and during the online search.

A similar arrangement exists for the sixteen laserdisk databases available in the Reference Division. Instructional handouts prepared by reference librarians or database producers are available at each workstation. Many of the laserdisk systems, such as the Silver Platter databases, have an extensive series of help screens. Most importantly, the area is staffed from 8 a.m. until closing ( 10 p.m. on weekdays and Sundays) by student assistants and classified staff members. The staff circu- 


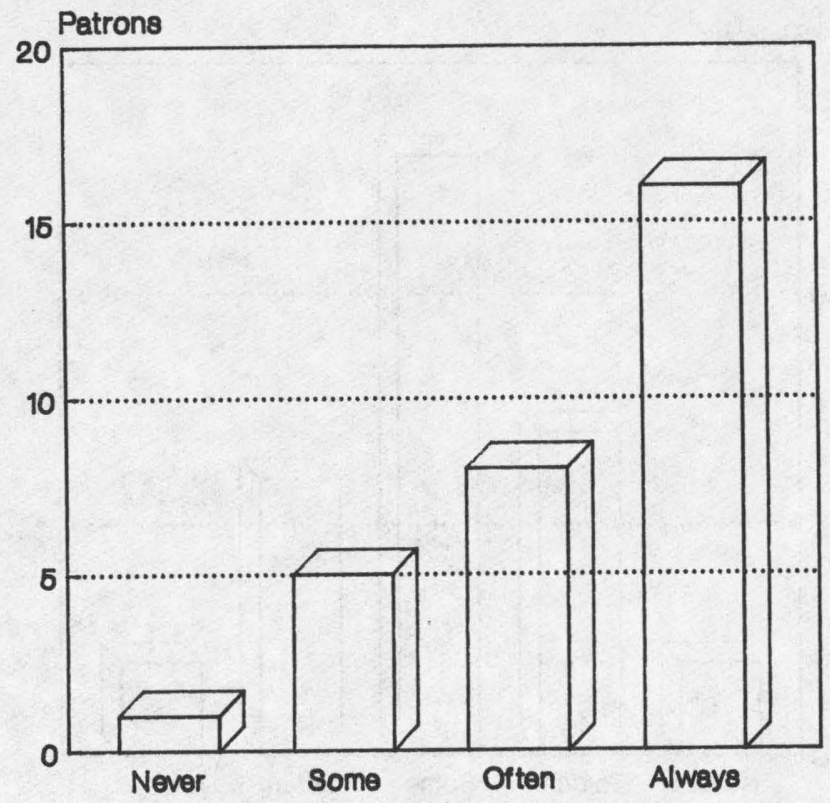

FIGURE 1

How Often Would You Use Online Updating?

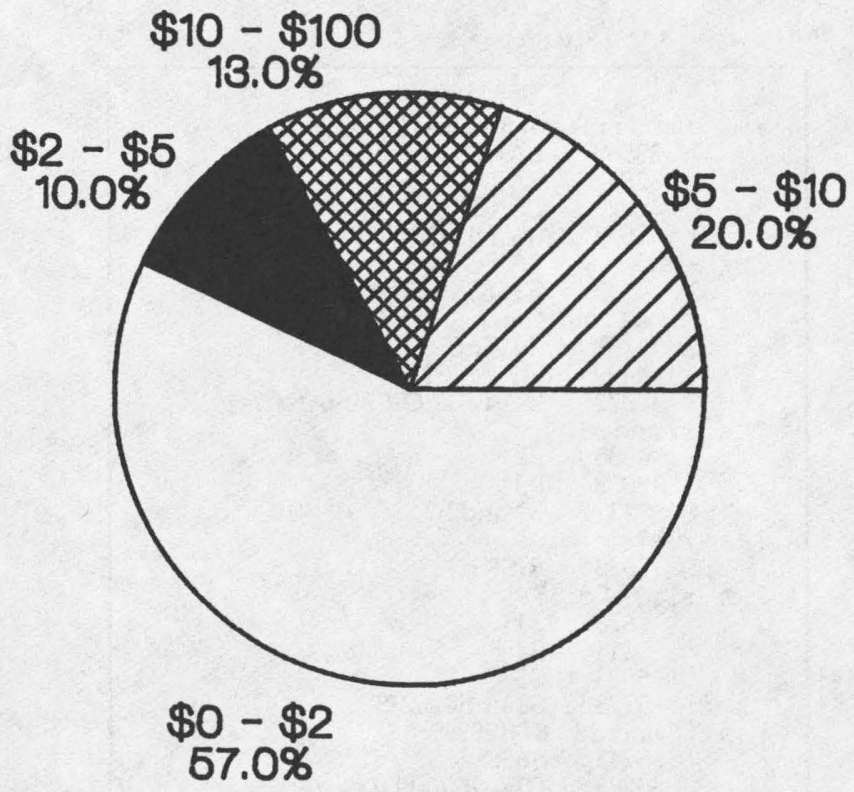

FIGURE 2

Cost of Searches 


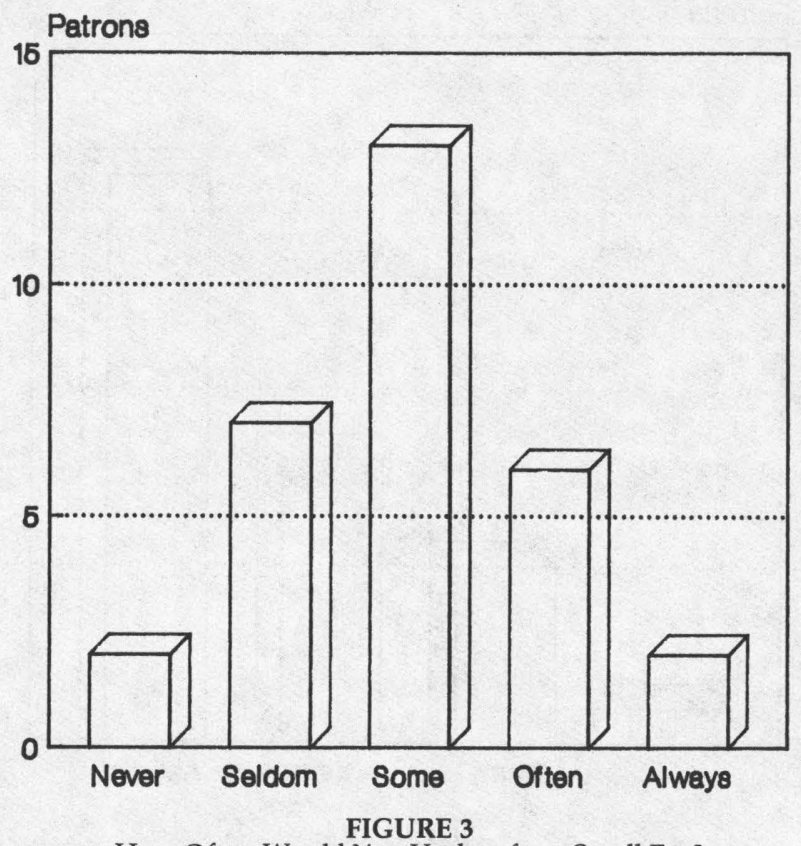

How Often Would You Update for a Small Fee?

? S (land or farm) and leas?

23569 LAND

62832 FARM

S1 673 (LAND OR FARM) AND LEAS?

? s stock?

S2 4635 STOCK?

? $\mathrm{S}$ invest? or financ?

13887 INVEST?

4499 FINANC?

S3 18072 INVEST? OR FINANC?

? $\quad \mathrm{s} \quad \mathrm{s} 2$ and s3

4635 S2

$18072 \quad \mathrm{~S} 3$

S4 $\quad 111 \quad \mathrm{~S} 2$ and S3

? s risk?

S5 5023 RISK?

? s $\mathrm{s} 1$ or $\mathrm{s} 4$ or s5

111 S4

5023 S5

S6 $5773 \quad \mathrm{~S} 1$ or S4 or S5

? s s6 and ud $=8710: 9999$
5773 S6
$65285 \mathrm{UD}=8710: \mathrm{UD}=9999$
S7 395 S6 AND UD $=8710: 9999$

FIGURE 4

"Farm Investment" Search Strategy 
late throughout the area providing detailed one-on-one instruction. Once again, help is readily available at anytime during the search.

Many participants had difficulty with the most basic principle of searchingselection of appropriate search terms. For example, a patron who was looking for articles on HAPLOIDS IN FORESTRY used the term FOREST as a keyword without applying truncation. Upon further questioning, it became apparent that the use of specific tree names would have been valuable. Searchers also neglected to use the scientific name (genus and species) of organisms in addition to the common name.

Few of the patrons used Boolean operators or if they did, most used them incorrectly. Out of the 45 searches, fewer than 10 used truncation. Not a single patron limited the search to specific fields (title, descriptor, etc.). The search strategy illustrated in figure 4 does incorporate the use of truncation and Boolean operators. Unfortunately, these techniques were used incorrectly (see figure 4). Even when the search was restricted to the latest online updates, 395 citations were found.

Despite the availability of onscreen, printed, and personal assistance, many end-users may not be as skillful at searching as librarians would like to believe. ${ }^{5}$ Some librarians assume that since the patrons are not asking for help, they do not need any, and that patrons are finding the material they need in the most efficient manner possible. The observations obtained during the course of this study indicate that this assumption is not accurate. The search strategy formulation problems encountered during this study are especially significant when taking into consideration that $90 \%$ of the participants indicated on their questionnaires that they had searched a laserdisk or online database within the past year. The majority of the participants $(60 \%)$ were graduate students with a strong interest in and commitment to their research. Yet, it is obvious that these searchers were not doing their online and/or laserdisk searches in the most effective way possible. These end-users, doing both online and ondisk searches, seemed satisfied that they were able to find something and find it quickly. They were impressed by the speed of the system and the large number of citations. When using both the online and ondisk systems, some of the participants happily printed out hundreds of citations. These observations also indicate that little attention is given to quality of the search results when the end-user can quickly print the citations and is charged little or nothing for the search.

Participants also experienced difficulty when switching between two separate systems such as Silver Platter and DIALOG. Logistically it was inconvenient to move from one search station to another. The necessity of using Silver Platter commands on the CD-ROM database and then adjusting to DIALOG commands for the online updating also provided participants with a major challenge. Most patrons needed a great deal of help. It quickly became apparent that they lacked the theoretical framework to make the transition smoothly. In addition, very few libraries could spare the staff needed to $\log$ patrons onto the online database and give them instruction on a second set of commands. This approach would become even more unrealistic if the online updates were provided "on demand" and not by appointment.

In our enthusiasm to embrace CDROM technology, librarians have neglected to make patrons aware of its drawbacks.

In our enthusiasm to embrace CD-ROM technology, librarians have neglected to make patrons aware of its drawbacks. Many of the patrons who participated in this research project were surprised to learn that Agricola on CD-ROM was not as current as its online counterpart. This type of response indicates that librarians should alert CD-ROM searchers to the possibility that they are not getting the most current information available. For many graduate students and faculty members, their ability to obtain the latest mate- 
rial is critical. These patrons especially should be aware of the lack of currency inherent in CD-ROM databases. One participant wrote "As a graduate student, I am encouraged to be on top of all current work in my field. Especially in state-ofthe-art, technical research the updated search is a must!" Libraries must provide patrons access to those recent citations missed by CD-ROM databases by subscribing to the online version. The responses provided by the participants of this study support the premise that online databases can be used to complement their CD-ROM counterparts to provide patrons with comprehensive coverage.

\section{CONCLUSIONS}

The majority of participants were eager to update their CD-ROM Agricola search with an online search. They thought that conducting an online search outweighed the time and effort involved. However, in spite of their enthusiasm, patrons were only willing to pay a modest fee ( $\$ 2$ to $\$ 5$ ) for the updating service. It is likely that patrons would supplement their CD-ROM searches with online searches if the service were available for a minimal charge. With a majority of searches costing under $\$ 5$, it may be feasible for libraries to provide online updates to $C D$-ROM database searches.

Patrons probably would use an online updating system only if it were convenient and easy to learn. Several currently available systems, such as those produced by Wilson and DIALOG, provide a smooth transition between the CD-ROM and online databases. Another advantage is that the same searching commands are used on both types of databases. However, subscribing to a system with automatic logon capability or a single command language is not the whole answer. Patrons still need instruction from library staff. As librarians gain more experience with end-users of both online and ondisk databases, it is becoming apparent that these CD-ROM systems are not as selfservice as they have been proclaimed to be. Participants in this study, most of whom had searched a database before, and all of whom had access to onscreen, printed, and personal assistance, were not using the system to its fullest capacity. The quantity of citations, speed, low cost, and hard copy seems to overshadow users' concerns for quality of citations.

Online databases are necessary complements to laserdisk databases in order to provide patrons with thorough and comprehensive information. These hybrid search systems will only be practical if they are convenient for patrons to use, available at little or no cost, and utilize the same search command structure. Products such as the DIALOG or Wilson systems are representative of the first step that the information industry must make to provide online updating for CD-ROM databases. Additionally, efforts to coordinate the use of these resources will be more successful if information professionals and industry members cooperate to assume the responsibility of integrating these services and providing effective instruction.

\section{REFERENCES}

1. Rick Meyer, "Strategies for Libraries," Bulletin of the American Society for Information Science 14:22 (Oct./Nov. 1987).

2. Ibid.

3. Vicki Anders, Wiley Laser Disk Service: Statistical Report, April 1988 (College Station, Tex.: Reference Division, Sterling C. Evans Library, Texas A\&M University, $\left.{ }^{\circledR} 1988\right)$.

4. Vicki Anders, Automated Information Retrieval Service: Annual Report 1987/88 (College Station, Tex.: Reference Division, Sterling C. Evans Library, Texas A\&M University, $\left.{ }^{\odot} 1988\right)$.

5. Stephen P. Harter and Susan M. Jackson, "Optical Disk Systems in Libraries: Problems and Issues," $R Q$ 27:519 (Summer 1988). 